\title{
Application of Choline Chloride as Natural Deep Eutectic Solvents for the Green Extraction of Phenolic Compounds from Rheum Ribes Leaves
}

\author{
Fatih Bildik (D) \\ ${ }^{1}$ İstanbul Technical University, Food Engineering Department, 34280, Maslak, Istanbul, Turkey. (e-mail: bildikfatih@itu.edu.tr).
}

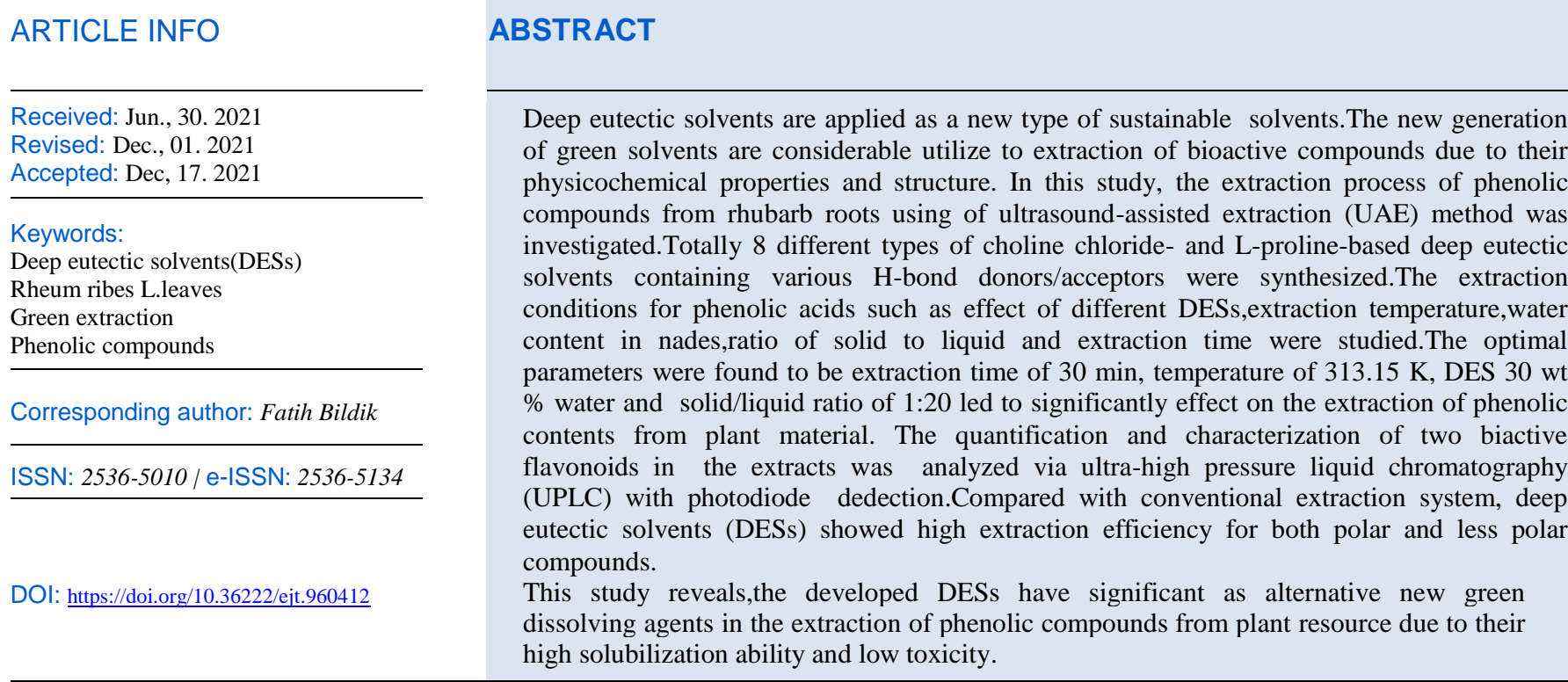

\section{INTRODUCTION}

Environmentally friendly (or green) solvents have a new type of fluids known as deep eutectic solvents (DES).DESs were discovered in 2003 by abbott et.al. [1]. DESs and DES-based material are alternatives to traditional solvents which are often toxic, environmentally unfriendly,volatile poorly biodegraded and flammable [2]. The new generation of liquids show many attractive physicochemical properties: low melting point, high solubility, biodegradable, nonvolatility, thermal stability and easy synthesized which can be composed of natural substances (e.g., salts, amino acids, organic acids and sugar, etc.) [3-6]. These solvents are consist of two or more salts that are melting point of eutectic mixtures salts are much lower than its starting substances. However, green deep eutectic solvents have been widely utilized for isolation and extraction of a variety of active compounds from medical plants [7]. The extraction method is also play important role. Ultrasonic assisted extraction method (UAE) has many advantages such as lower cost, higher yield and shorter extraction time, compared to the current extraction techniques [8]. There is capable strong electrostatic interaction between DES and phenolic
compounds.Thus, eutectic solvents is show to great potential to extract phenolic substances. We mainly studied on the DES combination of natural compounds such as alcohols, sugar, amine, organic acid and choline chloride. The main feature of choline chloride is that unique component properties such as high solubility, non-toxic, biodegradable quaternary amomnium salt [9]. In a previous study the capability of various $\mathrm{ChCl}$, lactic acid and oxalic acid based DES assisted by microwave were evaluated for extraction of different phenolic compounds from Lonicerae japonicae Flos such as chlorogenic acid, caffeic acid, 3,4-dicaffeoylquinic acid, and 4,5-dicaffeoylquinic acid [10]. In another similar research, the combination of DES and methanol-water was used to extract the phenolic acids from Herba artemisiae scopariae amoung different 12 DES, tetramethylammonium chloride/urea (1:4 mole ratio) was the best mixture for extraction Park and co-workers [11].

Moreover, phenolic acids was extracted using betaine-, L-proline-, or ChCl-based DES. Totally, for the extraction of different bioactive compounds including phenolic acids from five Chinese herbal medicines different DES combinations were tested [12]. Quercetin, kaempferol, and isorhamnetin also were extracted from Flos sophorae using different ratios 
of HBA (ChCl, L-proline and citric acid) and HBD (glycerol, xylitol, glucose, adonitol, or malic acid) [13].

Rhubarb (Rheum ribes L.) is a plant native to found mostly in eastern Turkey,Lubnanon,India and Iran. Rheum species are medicinal value herbs due to its source of one of anthroquinone.In Turkey, R.ribesis is locally called ''1sgin,usgun'. Its roots and leaves have been commonly consumed as raw or cooked. R.ribesis roots are used as pharmacetical raw material in the middle east [14,15].

Roots (and leaves) of this plant species are used against variety of diseases such as diabetes [16], obesity [16], hypertension [16], diarrhoea [17] and psychological disorder The roots of this species has been mainly comprised of antioxidant molecules such as quercetin, 5-desoxyquercetin, quercetin 3-O-galactoside, kaempferol-3-O-rhamnoside and quercetin 3-O-rutinoside [18].

In this study,ultrasonic assisted extraction method was utilized and other extraction-conditions including temperature,time and water content in DES were examined.This green method for extraction of two bioactive components in the R.ribes were used. The determination of flavonoid contents (quercetin and kaempferol) in this plant species was carried out utilizing high performace liquid chromatography-photodiode detection.

\section{MATERIAL AND METHODS}

\subsection{Chemicals and Materials}

The R.Ribes flowers were from Elazig, in eastern Turkey.The samples were dried and stored in the dark to use. Citric acid monohydrate, choline-chloride (99.0\%), $\mathrm{D}(+)$-glucose $(98.0 \%), \quad \mathrm{D}-(+)$-sucrose $(99.0 \%)$, urea (98.0\%), L-(+)-lactic acid( $98.0 \%)$ and L-proline (98.0\%) were supplied by Sigma-Aldrich. All others materials were used analytical grade.

\subsection{Instrumentation}

The quantify and identify the individual phenolic compounds were determined using HPLC analysis. The separation was carried out on Agilent (1100) UPLC chromatography equipped with a photodiode , an automatic column temperature oven, an autosampler, a quaternary pump and a Phenomenex C18 column (5 $\mu \mathrm{m}, 4.6 \times 150 \mathrm{~mm}$,). The mobile phase was water with $0.05 \%$ trifluoroacetic acid (A) and acetonitrile (B). The elution performed was set as follow: 0-10 minute, $10 \% \mathrm{~B}$; $10-20$ minute, $30 \% \mathrm{~B} ; 20-35$ minute, $40 \% \mathrm{~B} ; 35-50$ minute, $10 \% \mathrm{~B}$. The UV spectrum of kaempferol and quercetin were monitored at $\lambda=280 \mathrm{~nm}$. The constant flow rate was $1.0 \mathrm{~mL} / \mathrm{min}$. The standarts and samples were filtered utilizing Millipore $0.20 \mu \mathrm{m}$ filter.The calibration curves were depicted using different concentrations (10-50 ppm) of all compounds by dissolving them in solvent.

\subsection{Ultrasound-assisted extraction (UAE)}

UAE was performed using an ultrasonic equipment (Hielscher Ultrasonics, Teltow, Germany). The DES-based ultrasonic-assisted extraction process was performed as follows: Temperature was ranged from 30 to $65^{\circ} \mathrm{C}$, water content used in DES was between 5 to $50 \%$, liquid-solid ratio was ranged from 5 to $40 \mathrm{mLg}^{-1}$, extraction was performed 30-65 minutes and ultrasonic power was applied as $100 \mathrm{~W}$ and $30 \mathrm{kHz}$.

\subsection{Synthesis of deep eutectic solvents}

In the present study, 8 kinds of eutectic mixtures were prepared according to known studies $[3,19]$. Eight different DESs included pure choline chloride-glycerol (ChGly),pure choline chloride- lactic acid (ChLac), pure choline chloride$\mathrm{D}(+)$ glucose (ChGlu), pure choline chloride-urea (ChUr),pure choline chloride-citric acid (ChCA), pure choline chloride-D(+) glucose-citric acid (ChGluCA), pure choline chloride-urea-glycerol (ChUrGly), L-proline-lactic acid (ProLac).

Component mixture were prepared in deionized water and stirred at $60{ }^{\circ} \mathrm{C}$ till a transparent liquid obtained.After this time, natural deep eutectic solvents (NADESs) components were shaken again by a vortex for $1 \mathrm{~min}$, and then they were kept in a desiccator [20]. Abbreviations , appearances and molar ratios of the NADESs were displayed in Table 1. Ratios selected as 1:1 as described by Sylwia and Jakup, 2018 [7].

TABLE 1

LIST OF TESTED DESS FOR EXTRACTION

\begin{tabular}{|l|c|c|c|}
\hline Type & Name & Combination & Molar ratio \\
\hline DES-1 & ChLac & Choline chloride:lactic acid & $1: 1$ \\
\hline DES-2 & ChGly & Choline chloride:glycerol & $1: 1$ \\
\hline DES-3 & ChGlu & Choline chloride:glucose & $1: 1$ \\
\hline DES-4 & ChUr & Choline chloride:urea & $1: 1$ \\
\hline DES-5 & ChCA & Choline chloride:citric acid & $1: 1$ \\
\hline DES-6 & ChCAglu & Choline chloride:citric acid:glucose & $1: 1: 1$ \\
\hline DES-7 & ChUrGly & Choline chloride:urea:glycerol & $1: 1: 1$ \\
\hline DES-8 & ProLac & L-proline:lactic acid & $1: 1$ \\
\hline
\end{tabular}

\section{RESULTS AND DISCUSSION}

\subsection{Extraction effect of different DESs}

In this research, we use L-Cholineproline and choline chloride as the various types of H-bond donors and HBAs to prepare green solvents.Then, the extraction efficiency of eight analytes perform were compared.Based on comparison among all NADESs, ChCI-Lac based DES provided highest solubility $(510 \mathrm{mg} / \mathrm{mL})$.

The yields of polar and non-polar analytes continued as follows $\mathrm{ChLac}>$ ChGly $>$ ChUrGly $\approx \mathrm{MeOH}>\mathrm{ChUr}>$ ProLac $>$ ChCAGlu $>$ ChGlu $>$ ChCA.

ChLac $(359.8 \pm 0.02 \mathrm{mg} / \mathrm{mL})$ and ChGly $(340.1 \pm 0.01 \mathrm{mg} /$ $\mathrm{mL}$ ) showed the best extraction efficiency quercetin due to good ability of quercetin to form hydrogen bonds with DES. The solubility quercetin in methanol was $362.9 \pm 0.01$ $\mathrm{mg} / \mathrm{mL}, 196.7 \pm 0.01 \mathrm{mg} / \mathrm{mL}$ in ethanol. ProLac, ChCAGlu and ChCA showed lower capacity to dissolve target compounds.

These results are accordance with similar to previous reports $[21,22]$.The special structure of DES is critical for extracting analytes and is based on physicochemical interactions, other factors such as intrinsic properties and stability of the analytes should also be considered. However, there is a large number of hydrogen bonds allowing to be extraction efficiency increased which cause a positive effect the interactions between active compounds and NADES [20].Figure 1 show that the extraction effect of different DESs solvents. 


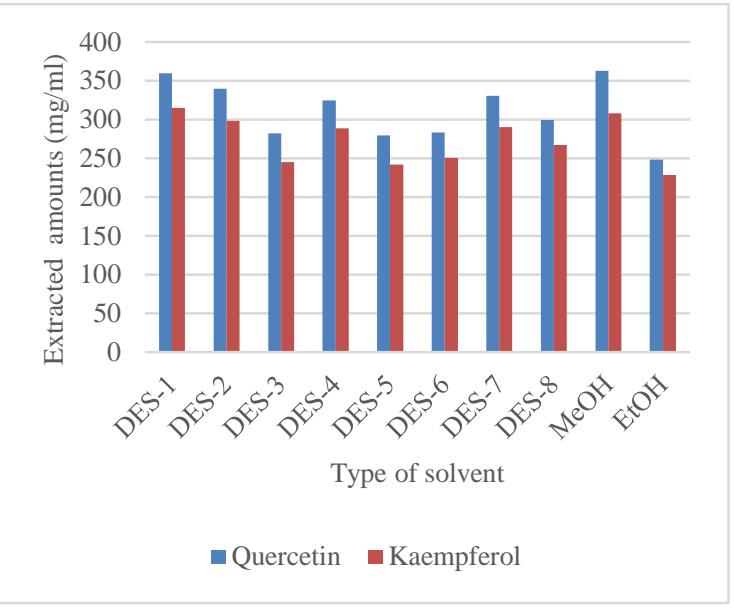

Figure 1.The extraction effect of different DESs solvents

Time is an important operational parameter in the completeness of the extraction yield. The sonication time has close related with extraction performed.The effect of extraction time between 15 and $60 \mathrm{~min}$ on the target compounds was examined. Figure 2 shows that the bioactive components completely extracted before up to 30 min. and thus, this extraction time was optimum. When the sonication time was increased with above $30 \mathrm{~min}$, extraction performed was decreased.A long extraction time potentially causes solvent polarity to change and also flavonoid contents interaction with ChCI-based DES to form polymer chain structure $[23,24]$.

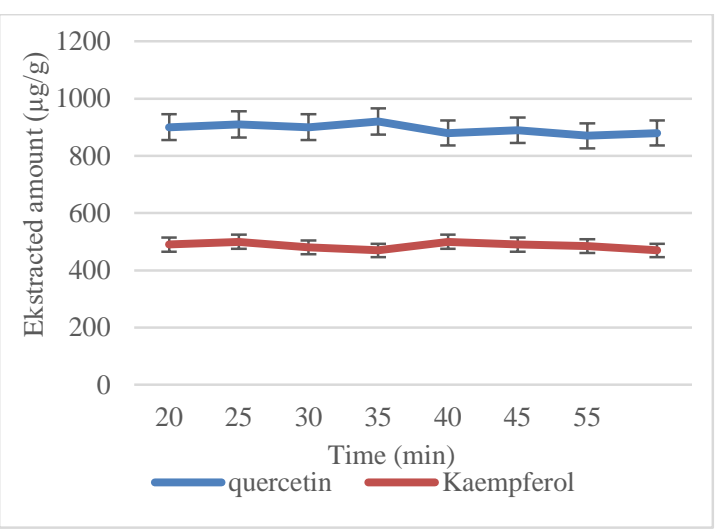

Figure 2.The extraction effect of sonication time

\subsection{Effect of the extraction temperature}

Temperature also affects extraction. The extraction temperature was examined between $30^{\circ} \mathrm{C}$ and $65{ }^{\circ} \mathrm{C}$ [25].When the working temperature was higher than 40 ${ }^{\circ} \mathrm{C}$,the yields were decrease in the amount of all extracted phenol.This is likely because the enhance the solvent viscosity, decrease the mass transfer, which affect the stabilization of the extraction capacity [26].

Although the ultrasonic power performed was achieved. when temperature was increased from 56 to $65{ }^{\circ} \mathrm{C}$.The targeted compounds significantly decomposed,as shown in Figure 3.These results showed a close relationship between extraction efficiency and extraction temperature.

\subsection{Effect of extraction time}

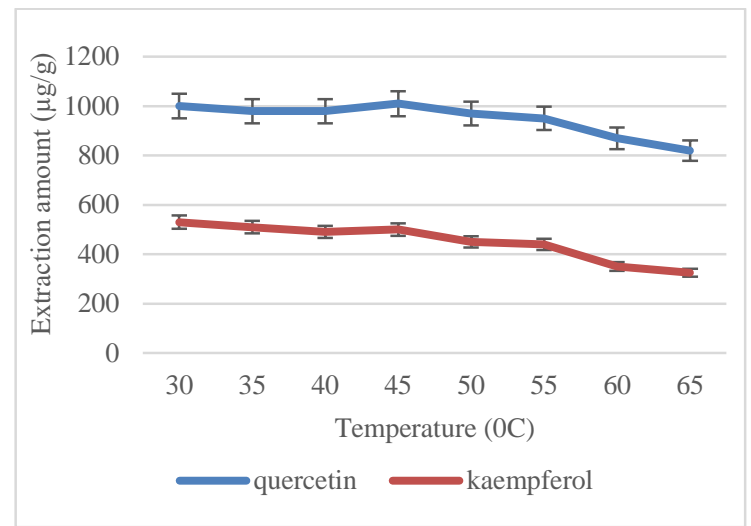

Figure 3.The extraction effect of temperature

\subsection{Effect of water content}

The effect of water amount in NADES on the extractability of target compunds was also examined. The addition of water in extraction system can impact on the extraction efficiency [16].The addition of different percentage water could eminently decrease the viscosity and could provide to a positive effect on polar components. With dilutions ranging between $\% 5$ and $50 \%$ of water content in NADES the extractability of target bioactive flavonoid was examined. As shown in figure 4, the extraction efficiencies of phenolic compounds reduced when the water content to more than $30 \%$ increased which cause a negatively impacts interactions between DES and analytes. The excessive high water content would result in the loss of occurring, H-bonds and as a result, interaction between the molecules gradually disappear. Results showed that, a concentration of $30 \%(\mathrm{v} / \mathrm{v})$ water in NADES could contributed to perform better effects extraction system.

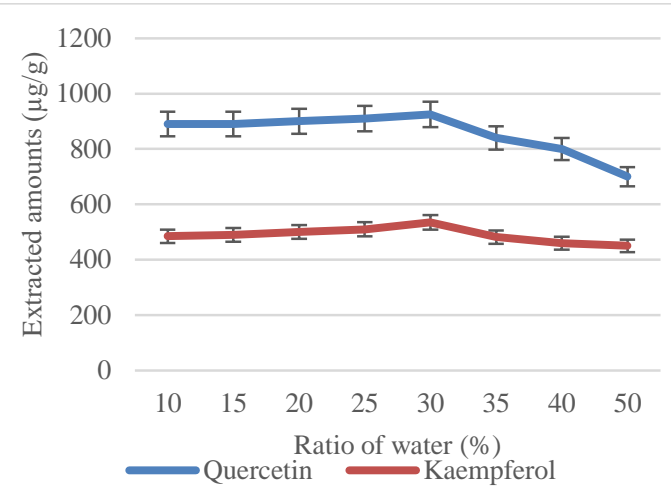

Figure 4.The extraction effect of water content

\section{CONCLUSION}

In the experiment,deep eutectic solvents (DESs) was utilized as more effective solvents for the dissolution of compounds, which could be associated with their hydrogen bonding interactions between the medium and components.

The biorenewable eutectic mixtures was established for extraction of quercetin and kaempferol from Rhubarb (Rheum ribes L.) roots in high yields.Overall, The parameters of different extraction conditions (i.e solid/liquid ratio,solvent concentration, temperature and time) were provide higher performance extraction for phenolic compounds.

The qualitative identification of individual active components were confirmed by high pressure liquid 
chromatography-photodiode. UPLC results showed that better compound separation was observed compared to HPLC methods. Quercetin and kaempferol were the most abundant phenolic acids identified in extract.

The deep eutectic solvents as new green solvents showed a high extraction capacity and efficiently extract bioactive compounds of diverse polarity.

\section{ACKNOWLEDGEMENT}

This study was carried out in the Food Engineering Department of Istanbul Technical University, Food Processing Laboratories.

\section{REFERENCES}

[1] A.P.Abbott, G. Capper, D.L. Davies, R.K. Rasheed, V. Tambyrajah, 'Novel solvent properties of choline chloride/urea mixtures',Chem. Commun., pp. 70-71, 2003.

[2] H. Wang, Y. Jia, X. Wang,', Physical-chemical properties of nickel analogs ionic liquid based on choline chloride',J. Therm. Anal. Cal., vol. 115, pp. 1779-1785, 2014.

[3] Y. Dai, J. Van Spronsen, G.J. Witkamp, R. Verpoorte, Y.H. Choi,'Natural deep eutectic solvents as new potential media for green technology','Anal. Chim. Acta, vol. 766, pp. 61-68, 2013a.

[4] Y. Dai, G.J. Witkamp, R. Verpoorte, Y.H. Choi,' Natural deep eutectic solvents as new extraction media for phenolic metabolites in safflower',Anal. Chem., vol. 85(13), pp. 6272-6278, 2013b.

[5] A.P.Abbott, G. Capper, D.L. Davies, R.K. Rasheed, V. Tambyrajah, 'Novel solvent properties of choline chloride/urea mixtures', Chem. Commun., pp. 70-71, 2003.

[6] R.P. Xin, S.J. Qi, C.X. Zeng, F.I. Khan, B. Yang, Y.H. Wang,' A functional natural deep eutectic solvent based on trehalose: structural and physicochemical properties,',Food Chem.,vol. 217, pp. 560-567, 2017.

[7] B. Sylwia, A. Jakup,'Development of a method based on natural deep eutectic solvents for extraction of flavonoids from food samples", Food Anal. Methods, vol. 11, pp. 1330-1344, 2018i

[8] X. Zhang, G.Teng, J. Tang," Deep eutectic solvents aqueous twophase system based ultrasonically assisted extraction of ursolic acid (UA) from Cynomorium songaricum Rupr.”, Chemical Engineering Communications., vol. 206, pp. 419-431, 2018-

[9] P. Xiao, D. Ming-Hui,Y. Xiao-Hui, Z. Chun-Jian, Z.Yuan-Gang, F.Yu-Jie," Green extraction of five target phenolic acids from Lonicerae japonicae Flos with deep eutectic solvent", Sep.Pur.Tech., vol. 157, pp. 249-257, 2016.

[10] X. Peng, M.H. Duan, Zhang Y.H, C.J. Zhao, Y.G Zu, Y.J.Fu,', Green extraction of five target phenolic acids from Lonicerae japonicae Flos with deep eutectic solvent',vol. 157, pp. 249-257, 2016, 157.

[11] H.E. Park, B.Tang, K.H. Row,'” Application of deep eutectic solvents a additives in ultrasonic extraction of two phenolic acids from Herba artemisiae scopariae", Anal. Lett., vol. 47 (9), pp.1476-1484, 2014.

[12] L. Duan, L.L. Dou, L. Guo, P. Li, E.H. Liu, "' Comprehensive evaluation of deep eutectic solvent in extraction of bioactive natural products", ACS Sustainable Chem. Eng., vol. 4(4), pp. 2405-2411, 2016.

[13] M.W. Nam, J. Zhao, M.S. Lee, J.H. Jeong J. Lee, ' Enhanced extraction of bioactive natural products using tailor-made deep eutectic solvent: application to flavonoid extraction from Flos sophorae'”, Green Chem., vol. 17 (3), pp. 1718-1727, 2015.

[14] K. Yoshiki, N. Gen-Ichiro, N. Itsuo, Y. Takashi,"Galloyl and hydroxy cinnamoyl glucoses from rhubarb",Phytochemistry, vol. 27(5), pp. 1473-1477, 1988.

[15] A. Shokravi, K. Agha Nasiri, "Synthesis of 1,2,3,4,5,6,7,8Octahydro-9-ethoxy-10-hydroxy-1-anthracenone (OEHA)",Iranian J. Chem. and Chem. Eng., vol.16, pp. 10-15, 1997.

[16] B.E. Abu-Irmaileh, F.U. Afifi, "Herbal medicine in Jordan with special emphasis on commonly used herbs",J.Ethnopharmacology, vol. 89, pp. 193-197, 2003.

[17] M. Tabata, E. Sezik, G. Honda, E. Yesilada, H. Fuki, K. Goto ,'Traditional medicine in Turkey III. Folk Medicine in East Anatolica, Van and Bitlis provinces",Int. J. Pharmacognosy, vol. pp. 32,3-12, 1994.

[18] F. Tosun, C. Akyuz-Kızılay,"Anthraquinones and flavonoids from Rheum ribes",J. Faculty of Pharmacy, Ankara, vol. 32, pp. 31-35, 2003.
[19] S. Bajkacz, J. Adamek,'Evaluation of new natural deep eutectic solvents for the extraction of isoflavones from soy products", Talanta, vol. 168, pp. 329-335, 2017.

[20] M. Zhaorui, Z. Jing, H.D. Hongxia, G. Yuanyuan, Z. Longshan, "Green and efficient extraction of four bioactive flavonoids from PollenTyphae by ultrasound-assisted deep eutectic solvents extraction",J. Pharmaceutical and Biomedical Analysis, vol. 161, pp. 246-253, 2018.

[21] E.M. Sánchez-Salcedo, P. Mena, C. García-Viguera, F. Hernández, J.J. Martínez,"(Poly)phenolic compounds and antioxidant activity of white (Morus alba) and black(Morus nigra) mulberry leaves: their potential for new products rich in phytochemicals",J. Funct. Foods, vol.18, pp.1039-1046, 2015.

[22] Y. Zou, S. Liao, W. Shen, F. Liu, C. Tang, C.Y.O. Chen, Y. Sun, "Phenolics and antioxidant activity of mulberry leaves depend on cultivar and harvest month in southern China",Int. J. Mol. Sci., vol. 13, pp. 16544-16553, 2012.

[23] Z. Pengfei, W. Xuping, L. Pengzhan, H. Jing, W. Chen, P. Mushui ,'Enhanced phenolic compounds extraction from Morus alba L. leaves by deep eutectic solvents combined with ultrasonic-assisted extraction", Industrial Crops \& Products, vol. 120, pp. 47-154, 2018.

[24] M. Wang, J. Wang, Y. Zhou, M. Zhang, Q. Xia, W. Bi, D.D.Y. Chen,"Ecofriendly mechanochemical extraction of bioactive compounds from plants with deep eutectic solvents", ACS Sustain. Chem. Eng., vol. 5, pp. 6297-6303, 2017.

[25] L. Duan, L.L. Dou, L. Guo, P. Li, E.H. Liu, "Comprehensive evaluation of deep eutectic solvents in extraction of bioactive natural products", ACS Sustain. Chem. Eng., vol. 4, pp. 2405-2411, 2016.

[26] Y. Dai, R. Verpoorte, Y.H. Choi,"Natural deep eutectic solvents providing enhanced stability of natural colorants from safflower (Carthamus tinctorius)",Food Chem., vol. 159, pp.116-121, 2014.

\section{BIOGRAPHIES}

Fatih Bildik obtained his BSc degree in Chemistry Department from Istanbul University (ITU) in 2002. He received the MSc., and $\mathrm{PhD}$. diploma in Chemistry Department from Istanbul Technical University (ITU) in 2006 and 2016 respectively, and PhD degrees in Graduate Faculty of Science and Letters, Department of Chemistry of the same university in 2016.

His research interests are polymer technologies, especially the synthesis and electrical properties of liquid crystal polymer.He has recently focused on food chemistry. In 2007 he joined the Engineering Faculty, İstanbul Technical University as a research assistant. He is active in teaching and research in instrumental systems. 